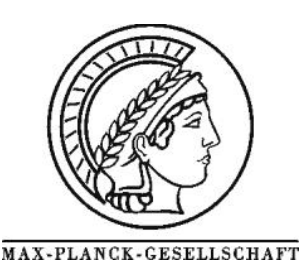

\title{
Iron impregnation on the amorphous shell of vapor grown carbon fibers and the catalytic growth of secondary nanofibers
}

\author{
W. Xia ${ }^{\mathrm{a} *}$, H. Bitter ${ }^{\mathrm{b}}$, D. S. Su${ }^{\mathrm{c}}$, J. Qian ${ }^{\mathrm{a}}$, M. Muhler ${ }^{\mathrm{a}}$ \\ ${ }^{a}$ Laboratory of Industrial Chemistry, Ruhr University Bochum, D-44780 Bochum, Germany \\ ${ }^{\mathrm{b}}$ Department of Inorganic Chemistry and Catalysis, Debye Institute, Utrecht University, PO Box 80083, \\ 3508 TB Utrecht, the Netherlands \\ ${ }^{\mathrm{c}}$ Department of Inorganic Chemistry, Fritz Haber Institute of the Max Planck Society, D-14195 Berlin, Germany
}

* Corresponding author: e-mail wei.xia@ techem.ruhr-uni-bochum.de, Fax: +49-234-32-14115; Tel: +49-234-3222341

Received 8 February 2008, Received in revised form 4 June 2008, Accepted 9 July 2008, Available online 13 July 2008

\begin{abstract}
Vapor grown carbon fibers (VGCFs) with diameters of several microns were synthesized and investigated by high resolution transmission electron microscopy. It was found that the shell of the VGCFs consisted of densely-packed domains embedded in loosely-packed matrix, and both were highly amorphous. Regular edge planes as observed on the surface of fishbone nanofibers do not exist on VGCFs. Hence, surface treatment is more important for the deposition of catalysts. Ammonium ferric citrate (AFC) was employed for the impregnation of iron, where the high viscosity of the aqueous solution of AFC is beneficial. Calcination was found to be a key step to improve the dispersion of the iron particles, which can be attributed to enhanced interactions between iron and carbon due to the gasification of carbon occurring at the iron-carbon interface. Quantitative analysis by X-ray photoelectron spectroscopy showed that the calcination of the supported AFC led to a higher atomic concentration of iron on the surface, indicating smaller particle size and higher dispersion. Secondary carbon nanofibers were grown subsequently on the VGCFs from cyclohexane. The specific surface area was enhanced considerably, from less than $1 \mathrm{~m}^{2} \mathrm{~g}^{-1}$ to $106 \mathrm{~m}^{2} \mathrm{~g}^{-1}$ after the growth of the secondary nanofibers. The obtained composites are promising materials as structured support in heterogeneous catalysis.
\end{abstract}

Keywords: Composites; Vapor growth; Catalytic processes; Morphology

\section{Introduction}

Carbon materials are widely used as supports for heterogeneous catalysis due to their specific characteristics including resistance to acid/basic media, controllable surface and porosity, and easy recovery of precious metals [1]. A variety of methods have been developed for the preparation of supported catalysts in recent years including impregnation and drying [2], deposition precipitation [3], and chemical vapor deposition (CVD) [4, 5]. For the wetting methods, the metal precursor may be crucial to achieve a homogeneous distribution. Geus et al. [6, 7] employed ammonium ferric (III) citrate and obtained homogeneous distribution of iron nanoparticles, whereas a simple salt like iron nitrate proved to be less suitable for this purpose due to low viscosity of the precursor solution. The CVD method is superior when the particle size, size distribution, and homogeneity are concerned. For all the methods, the surface properties of the carbon substrate play a key role for the deposition of nanoparticles. Surface treatment or functionalization is frequently employed to modify the hydrophobic surface of carbon fibers or carbon nanotubes. A variety of functionalization methods were reported including nitric acid treatment, oxygen plasma treatment, oxidation in air and treatment by supercritical fluids etc [8, 9]. The treatment can introduce oxygen-containing functional groups as well as surface defects, which act as anchors for subsequently adsorbed molecules $[10,11]$.

The vapor grown carbon fibers (VGCFs) can be prepared by pyrolysis of hydrocarbons over transition metal 
catalysts such as iron, nickel or their alloys [12]. Thermogravimetric studies indicate that the shell of VGCFs is less ordered compared to the core. The shell is grown by pyrolysis of carbon, whereas the core originates from catalytic growth $[13,14]$. Although the growth of VGCFs has been intensively studied, little is known about the bulk and surface structure of the presumably disordered shell of the VGCFs. The specific surface area of VGCFs is rather small $\left(<1 \mathrm{~m}^{2} \mathrm{~g}^{-1}\right)$ because of their large diameters, which are frequently in the range of 1 to $10 \mu \mathrm{m}$. Therefore, the growth of secondary filaments is an effective route to increase the specific surface area, aiming at the application of the VGCFs in catalysis [15]. This strategy was also employed by Downs and Baker to improve the inter-laminar shear strength in PAN-fiber-reinforced polymer composites $[16,17]$. We have studied the CVD of iron on carbon nanofibers and the subsequent branching catalyzed by the iron nanoparticles [5]. The use of carbon fibers as substrate for the growth of nanofibers was reported recently [18-24]. However, the homogeneity appears to be poor, which may result from the catalyst precursor, the carbon source, and the lack of calcination step etc. We focus here on the irondeposition process on the shell of VGCFs, and demonstrate the effect of the calcination on the growth of secondary nanofibers. Cyclohexane was used as carbon source instead of frequently employed methane. Thus, the growth temperature was considerably lowered.

\section{Experimental}

The reactor used for the fiber growth consists of a horizontal quartz tube with a length and inner diameter of $100 \mathrm{~cm}$ and $3 \mathrm{~cm}$, respectively. Ammonium ferric citrate (14.5-16 wt \% Fe, Fluka Chemie, denoted as AFC in the following text.) was used as catalyst precursor. The parent and the secondary fibers were grown from cyclohexane (Baker, 99.0\%), which was fed to the reactor by passing a mixture of hydrogen (99.99999\%) and/or helium (99.9999\%) through a saturator containing cyclohexane at room temperature. The feeding of gases was controlled by mass flow controllers. The VGCFs were grown on graphite foil (Union Carbide, Grafoil ${ }^{\circledR}$ ). The foil was wetted by an aqueous solution of AFC $\left(0.05 \mathrm{mg} \mathrm{cm}^{-2}\right)$ and dried at room temperature. The foil was then loaded to the tube reactor and the VGCFs were grown at $1323 \mathrm{~K}$ for $60 \mathrm{~min}$ from cyclohexane (through hydrogen and helium, 2:1, $37.5 \mathrm{sccm}$ total). The VGCFs were harvested from the foil and used as substrate for the growth of secondary nanofibers.

The as-grown VGCFs were refluxed in boiling nitric acid $(65 \%)$ for $3 \mathrm{~h}$, followed by filtration, washing and drying. The treated-VGCFs were then mixed with an AFC solution of predetermined amount, corresponding to a $\mathrm{Fe}$ loading of about $10 \mathrm{wt} \%$ on VGCFs. The mixture was dried by circulating air at $323 \mathrm{~K}$. The calcination of the AFC-loaded VGCFs were carried out under dynamic air for $90 \mathrm{~min}$ at $573 \mathrm{~K}$. For the growth of secondary nanofibers, the iron-loaded VGCFs were first reduced by heating to
$1023 \mathrm{~K}$ in hydrogen and helium $(1: 1,200 \mathrm{sccm}$ total), with a holding period of $20 \mathrm{~min}$ at $673 \mathrm{~K}$. Cyclohexane was subsequently introduced by bubbling with helium (37.5 $\mathrm{sccm})$ or a mixture of hydrogen and helium $(2: 1,37.5 \mathrm{sccm}$ total). The growth was carried out for $30 \mathrm{~min}$ and then the reactor was cooled down to room temperature.

The samples for X-ray photoelectron spectroscopy (XPS) measurement were prepared as follows: iron loaded VGCFs, both calcined and non-calcined, were heated to $1023 \mathrm{~K}$ under the same conditions (in hydrogen and helium, 1:1, $200 \mathrm{sccm}$ total) like the growth of secondary nanofibers, and cooled down under helium before introducing cyclohexane. The Pyrograf III nanofibers (pyrolytically stripped, diameter 70-200 nm, length 30-100 $\mu \mathrm{m}$ ) used for thermogravimetry (TG) were supplied by Applied Sciences Inc. (Ohio, USA). The VGCFs (diameter $c a .6 \mu \mathrm{m}$ ) for transmission electron microscopy (TEM) measurement were grown from methane $(99.995 \%)$ diluted in hydrogen $(3: 7,150 \mathrm{sccm})$ at $1423 \mathrm{~K}$ for $90 \mathrm{~min}$. The growth was discussed in detail elsewhere [13]. For the TEM measurement (Philips CM 200 FEG), the VGCFs were first embedded in polymer to form composite, which was then cut perpendicular to the axial direction and a thin cross-section of the composite containing VGCFs was obtained.

The morphology was studied by scanning electron microscopy (LEO Gemini 1530). Thermogravimetry was performed with a Cahn TG 2131 thermobalance. A quadrupole mass spectrometer (Omnistar) was coupled with the TG to analyze the released gases. The BET surface area was determined by nitrogen physisorption at $77 \mathrm{~K}$. The samples were out-gassed at $573 \mathrm{~K}$ until the pressure was lower than $500 \mathrm{~Pa}$. XPS measurements were carried out in a UHV set-up equipped with a Gammadata-Scienta SES 2002 hemispherical analyzer. The base pressure in the measurement chamber was $2 \times 10^{-10} \mathrm{mbar}$. Monochromatic Al $\mathrm{K}_{\alpha}(1486.6 \mathrm{eV} ; 14 \mathrm{kV} ; 55 \mathrm{~mA})$ was used as incident radiation. A pass energy of $200 \mathrm{eV}$ and a slit width of 0.2 $\mathrm{mm}$ were chosen. An energy resolution better than $1 \mathrm{eV}$ was achieved. Charging effects were compensated by a flood gun, and binding energies were calibrated using the main $\mathrm{C} 1 \mathrm{~s}$ peak at $284.5 \mathrm{eV}$ as internal standard.

\section{Results and Discussion}

The crystal structure of carbon nanofibers or nanotubes has been well established by a variety of techniques including high resolution TEM, Raman spectroscopy etc. The structure of VGCFs, however, was seldom studied in detail due to their large dimensions, which is typically a few microns in diameter. Fig. 1A shows a SEM micrograph of VGCFs grown from methane at $1423 \mathrm{~K}$. The surface exhibits ring structure with little roughness in nano-scale. Two mechanisms contribute to the growth of the VGCFs, i.e., the catalytic growth and the thermal decomposition. Carbon filaments initiated from catalytic growth at low temperatures, where nanofibers were usually obtained, and thickened by thermal decomposition at higher tempera 

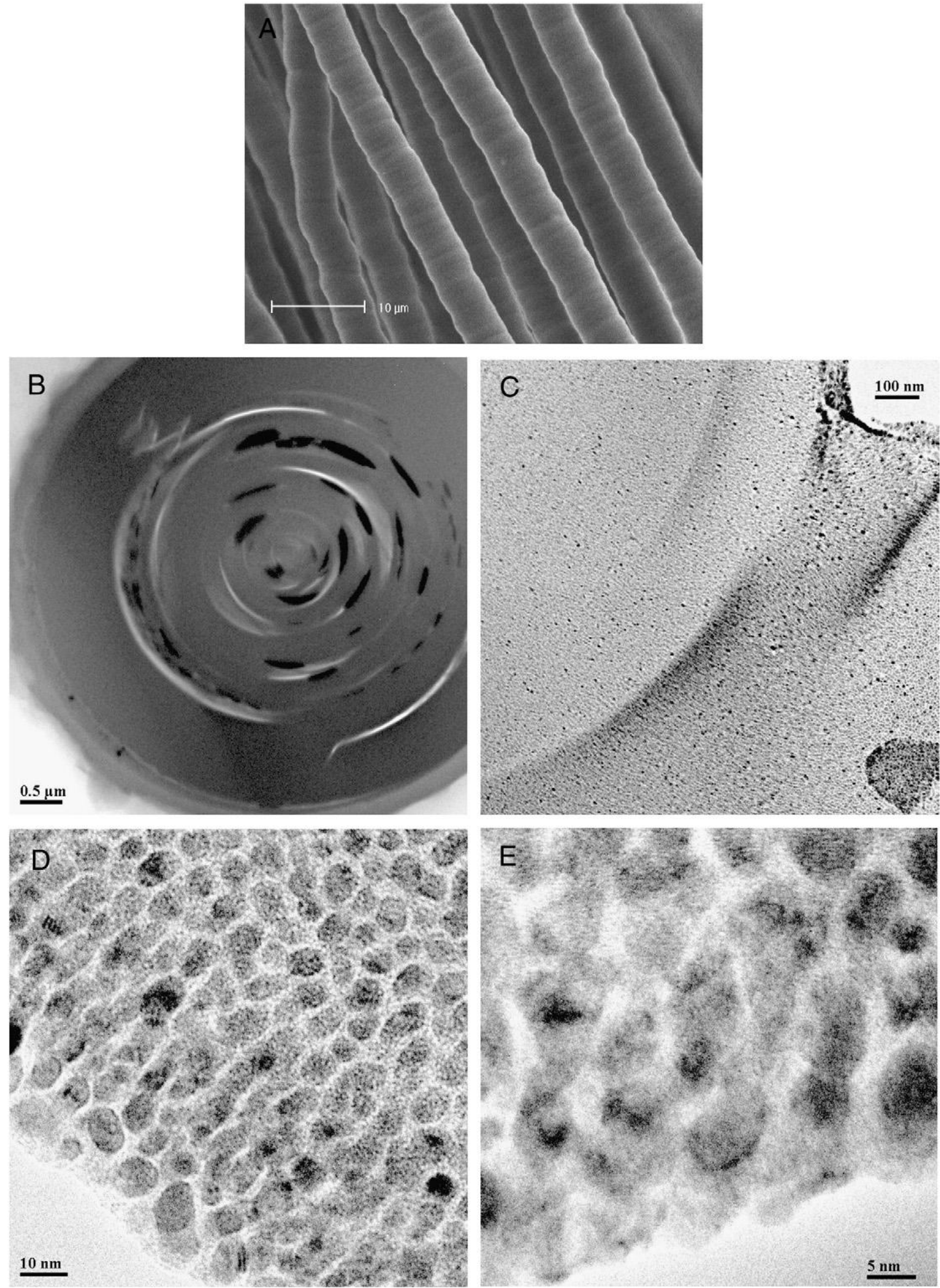

Fig. 1: (A) SEM micrograph of the parent VGCFs; (B) TEM image of the cross-section of a VGCF; (C)-(E) TEM images of the shell of the VGCF with different magnifications. The VGCFs were grown from $\mathrm{CH}_{4}$ diluted in $\mathrm{H}_{2}$ (3:7) at $1423 \mathrm{~K}$ with Fe nanoparticles as catalyst.

tures, where microfibers are commonly obtained. The cross-section of VGCFs was examined by high resolution TEM. Fig. 1B displays an overview of the cross-section of a VGCF. The layer structure is clearly visible in the TEM image. It can be seen from Fig. 1C and 1D that the shell of the VGCF comprises of high density domains embedded in low density matrix. The resolution in the micrograph of Fig. $1 \mathrm{E}$ is high enough to distinguish the graphite (or graphene) sheets (typically $\mathrm{d}=0.34 \mathrm{~nm}$ ), if there is some structural ordering. However, no regular structures can be observed in both the high density domains and the low density matrix, which indicates that the shell of the fiber is 
highly disordered. It is known that in fishbone nanofibers edge planes of graphene sheets expose to the surface, which can be anchoring points for foreign atoms. However, this is not the case for VGCFs due to the highly disordered structure, where regular edge planes do not exist on the surface due to the lack of preferred orientation. Therefore, the deposition of catalysts on the VGCF surface can be expected to be more difficult.

To modify the inert surface of the as-grown VGCFs, nitric acid was used to introduce oxygen-containing functional groups as well as surface defects, which act as anchors for foreign atoms. The impregnation process is very important for the catalyst preparation. However, the thermal treatment after impregnation also plays a major role. We focus here on the calcination process of the AFCloaded VGCFs ( 10 wt \% Fe), as compared to the AFC itself.

The calcination of the AFC was studied by TG-MS in a mixture of oxygen and helium (1:4) at a total flow rate of $100 \mathrm{sccm}$ and a heating rate of $5 \mathrm{~K} \mathrm{~min}^{-1}$. Pure AFC was studied for comparison. Based on the TG-MS results, five steps can be derived for the thermal decomposition of pure $\mathrm{AFC}$ in oxygen, as denoted by five peak temperatures, i.e., $400 \mathrm{~K}, 480 \mathrm{~K}, 520 \mathrm{~K}, 570 \mathrm{~K}$, and $655 \mathrm{~K}$ (Fig. 2A). Crystal $\mathrm{H}_{2} \mathrm{O}$ as well as absorbed $\mathrm{H}_{2} \mathrm{O}$ was first released at around $400 \mathrm{~K}$. The following three steps, corresponding to the 3 peaks in the mass spectra, were resulted from the release of $\mathrm{CO}_{2}(\mathrm{~m} / \mathrm{z}=44), \mathrm{NH}_{3}(\mathrm{~m} / \mathrm{z}=17), \mathrm{H}_{2} \mathrm{O}(\mathrm{m} / \mathrm{z}=18)$ and $\mathrm{CO}$ $(\mathrm{m} / \mathrm{z}=28)$. The release of $\mathrm{CH}_{4}(\mathrm{~m} / \mathrm{z}=16)$ and nitrogen oxides $(m / z=30,46)$ were also detected as weak signals in the mass spectra. Further heating results in the release of carbon oxides (mainly $\mathrm{CO}_{2}$ ) at about $70 \mathrm{~min}$, or $655 \mathrm{~K}$ (trace $\mathrm{m} / \mathrm{z}=44$ ). The intermediate at $630 \mathrm{~K}$ (before the 655 $\mathrm{K}$ peak) therefore can be assumed to be $\mathrm{Fe}_{2} \mathrm{O}_{\mathrm{n}}\left(\mathrm{CO}_{3}\right)_{3-\mathrm{n}}$ [25]. Calculations from the final product (mainly $\mathrm{Fe}_{2} \mathrm{O}_{3}$ ) and the total weight loss gave $14.9 \mathrm{wt} \% \mathrm{Fe}$, which is in agreement with the technical data of the AFC, i.e. 14.5 16.0 wt \% of Fe. It can be seen from Fig. 2B that the calcination of supported AFC does not show a peak similar to the one at 70 $\min (655 \mathrm{~K})$ in trace $m / z=44$ of Fig. $2 \mathrm{~A}$, which indicates that the decomposition of AFC is not complete at the calcination temperature of $573 \mathrm{~K}$ and pure $\mathrm{Fe}_{2} \mathrm{O}_{3}$ is not yet obtained. The intermediate is likely to be $\mathrm{Fe}_{2} \mathrm{O}_{\mathrm{n}}\left(\mathrm{CO}_{3}\right)_{3-\mathrm{n}}$, which releases $\mathrm{CO}_{2}$ at higher temperatures around $655 \mathrm{~K}$.

The reduction of the calcined AFC, both unsupported and VGCF-supported, was subsequently performed at a heating rate of $10 \mathrm{~K} \mathrm{~min}^{-1}$, with a holding period of $20 \mathrm{~min}$ at $673 \mathrm{~K}$, finally up to $973 \mathrm{~K}$, which is the same temperature program as the growth of the secondary nanofibers, except for the final temperature. The holding at $673 \mathrm{~K}$ aimed to achieve a total reduction and increasing the time of annealing of the iron nanoparticles. For the unsupported sample, the weight loss shows two steps (Fig. 3A top), centred at about $560 \mathrm{~K}$ and $673 \mathrm{~K}$ respectively. The first step at $560 \mathrm{~K}$ can be mainly assigned to the release of $\mathrm{H}_{2} \mathrm{O}$ due to the reduction of $\mathrm{Fe}_{2} \mathrm{O}_{3}$ to $\mathrm{Fe}_{3} \mathrm{O}_{4}$. The weak MS peak of $\mathrm{CO}_{2}(\mathrm{~m} / \mathrm{z}=44)$ at $560 \mathrm{~K}$ may be attributed to the decomposition of the $\mathrm{Fe}_{2} \mathrm{O}_{\mathrm{n}}\left(\mathrm{CO}_{3}\right)_{3-\mathrm{n}}$ residue. The second step
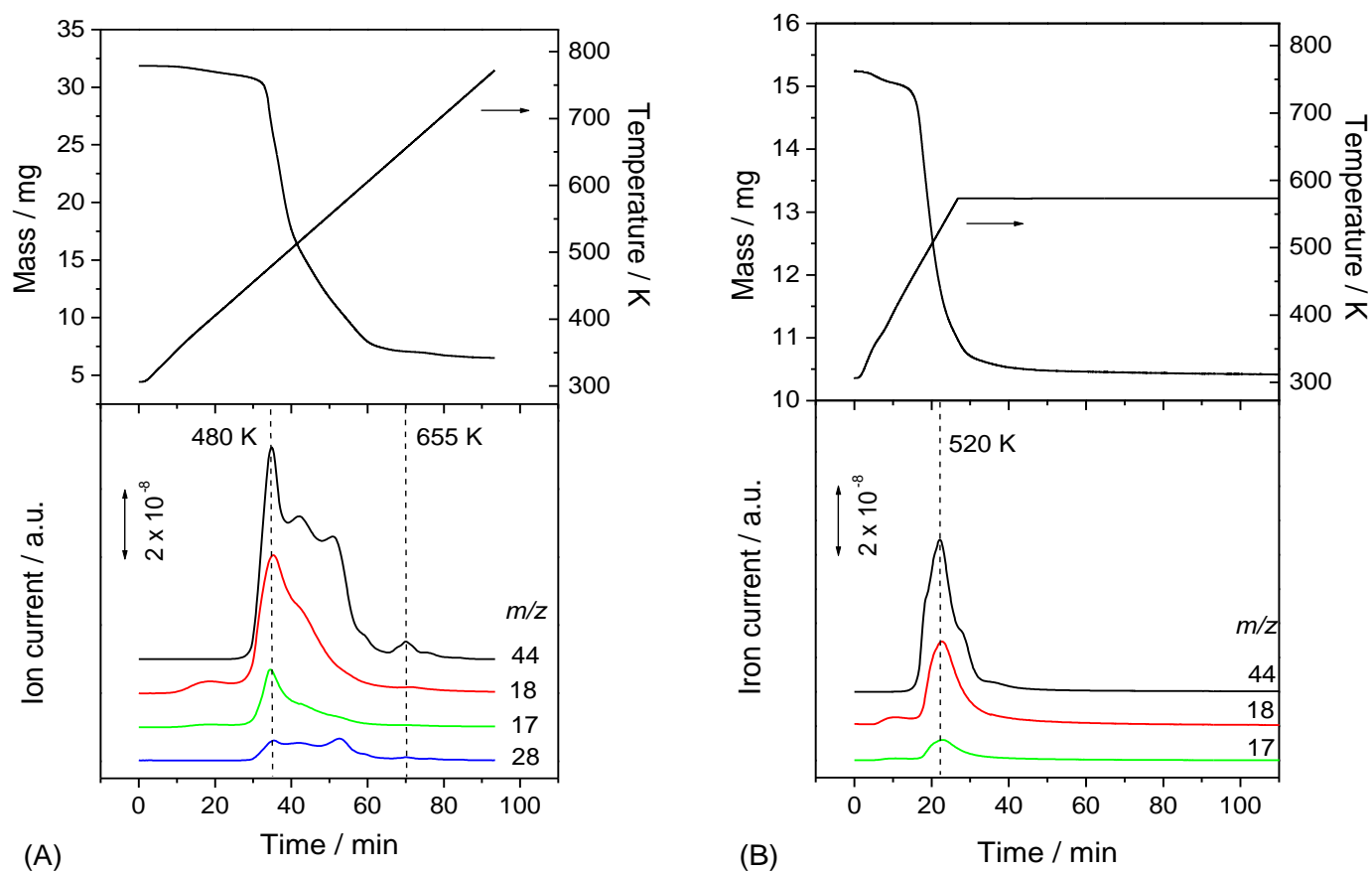

Fig. 2: Thermogravimetric weight loss curves in a mixture of oxygen and helium (1:4 at $100 \mathrm{sccm})$ and the correspondingly released gas species as detected by mass spectrometry. (A) AFC; (B) VGCF-supported AFC. 

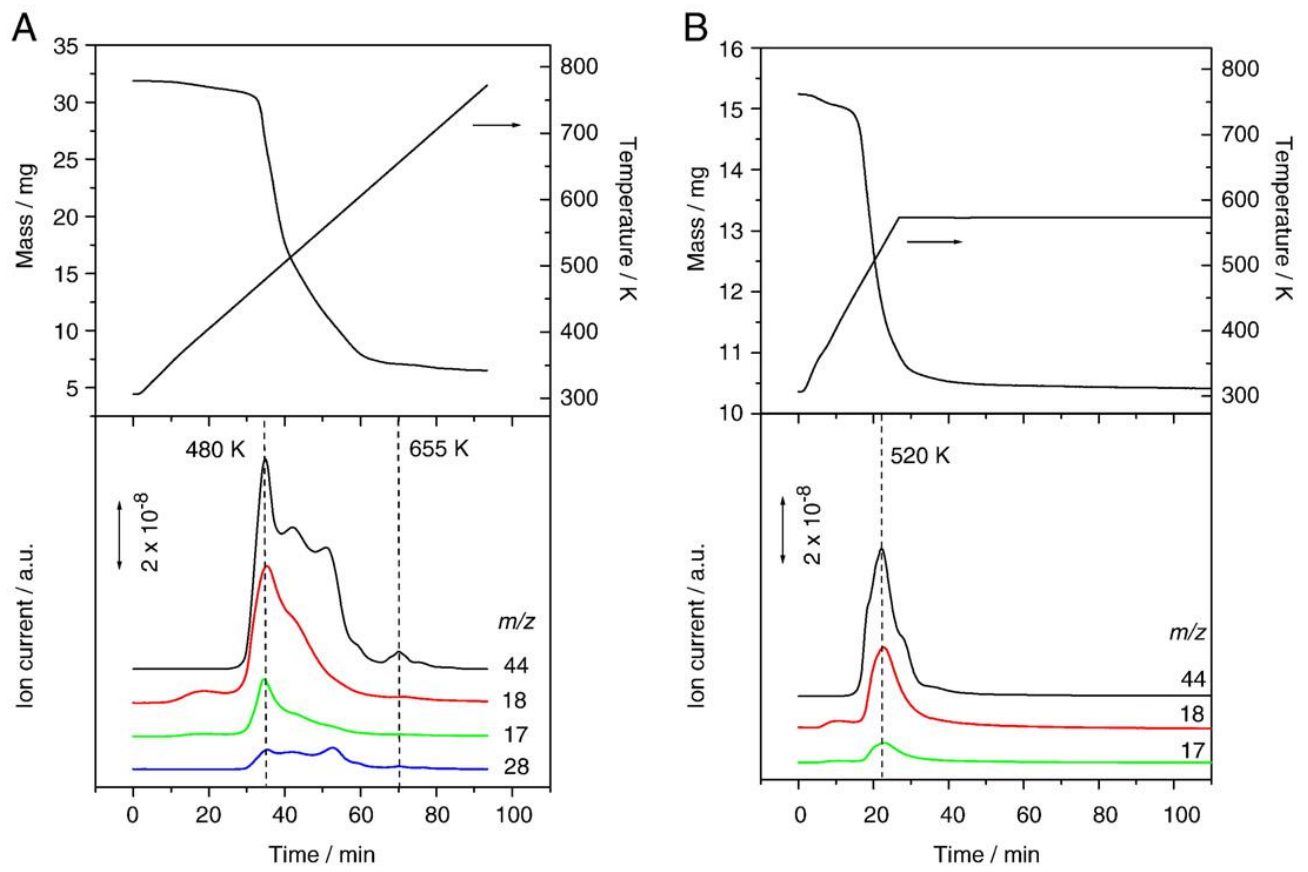

Fig. 3: Thermogravimetric weight loss curves in a mixture of hydrogen and helium (1:1 at $100 \mathrm{sccm})$ and the correspondingly released gas species as detected by mass spectrometer. (A) pure AFC, calcined; (B) VGCF-supported AFC, calcined.

at $673 \mathrm{~K}$ results from the reduction of $\mathrm{Fe}_{3} \mathrm{O}_{4}$ to metallic $\mathrm{Fe}$. Two similar steps at lower temperatures occur on the VGCF-supported sample as seen from the TG weight loss curve (Fig. 3B top). The first step related to $\mathrm{Fe}_{2} \mathrm{O}_{\mathrm{n}}\left(\mathrm{CO}_{3}\right)_{3-\mathrm{n}}$ and reduction of $\mathrm{Fe}_{2} \mathrm{O}_{3}$ to $\mathrm{Fe}_{3} \mathrm{O}_{4}$ appears weaker presumably due to the significantly decrease in the amount of $\mathrm{Fe}$ species in the supported sample. Nevertheless, the second step terminates at $34 \mathrm{~min}(635 \mathrm{~K})$, before reaching the steady state temperature of $673 \mathrm{~K}$, whereas the second step of the unsupported sample is terminated at $45 \mathrm{~min}$ at $673 \mathrm{~K}$, about $11 \mathrm{~min}$ after reaching the steady state temperature. The particle size may account for the difference of the 11 min. The particles of the supported sample are smaller, and consequently the reduction time is shorter. The decrease of mass at high temperatures after $70 \mathrm{~min}$ is mainly due to the Fe-catalysed reaction of $\mathrm{H}_{2}$ with the carbon support, as evidenced by the build-up of $\mathrm{CH}_{4}$ (trace $\mathrm{m} / z=16$ in Fig. 3B bottom).

The effect of the calcination step on the preparation of VGCF-supported iron catalysts was studied by XPS. Fig. 4A and 4B shows the XP spectra of two reduced samples (heated to $1023 \mathrm{~K}$ under helium and hydrogen) with and without calcination step at $573 \mathrm{~K}$. In both cases the samples were exposed to air during transfer to the XPS setup. The Fe $2 p$ core levels are split into $2 p_{1 / 2}$ and $2 p_{3 / 2}$ components due to the spin-orbit coupling. The $\mathrm{Fe} 2 \mathrm{p}_{3 / 2}$ core level appears at $711.2 \mathrm{eV}$, which is characteristic for the $\mathrm{Fe}^{3+}$ species and agree well with the literature data [26, 27]. ObviObviously, the metallic iron nanoparticles resulted from the heat treatment in reduction atmosphere were partially oxidized by oxygen and/or water vapor (moisture) during sample transfer in air. A significant increase of the intensity of Fe $2 p$ spectra is observed in the calcined sample, corre
Table 1: Quantitative XPS results of the iron loaded VGCFs samples prepared with or without the calcination step. The samples were reduced by heating to $1023 \mathrm{~K}$ in a mixture of $\mathrm{H}_{2}$ and $\mathrm{He}$ (1:1 at $200 \mathrm{sccm}$ ), with a holding period of $20 \mathrm{~min}$ at $673 \mathrm{~K}$. The samples were exposed to air during transfer to the XPS setup.

\begin{tabular}{|c|c|c|c|c|}
\hline Sample (Fe/VGCF) & Bement & $\begin{array}{l}\text { Sensitivity } \\
\text { factor [33] }\end{array}$ & Area $\left(\times 10^{5}\right)$ & $\begin{array}{l}\text { Surface atamic } \\
\text { concentration }\end{array}$ \\
\hline \multirow[t]{3}{*}{ Without calcination step } & C.1s & 0.25 & 8221 & $92.6 X$ \\
\hline & $01 \mathrm{~s}$ & 0.66 & 15.16 & $65 \%$ \\
\hline & Fe $2 p$ & 3.0 & 9.78 & 0.98 \\
\hline \multirow[t]{3}{*}{ With calcination step } & C 1s & 0.25 & 73.94 & $8537 x$ \\
\hline & $01 \mathrm{~s}$ & 0.66 & 26.11 & 11.48 \\
\hline & Fe $2 p$ & 3.0 & 3428 & $33 x$ \\
\hline
\end{tabular}

The samples were reduced by heating to $1023 \mathrm{~K}$ in a mixture of $\mathrm{H}_{2}$ and $\mathrm{He}(1: 1$ at $200 \mathrm{sccm})$, with a holding period of $20 \mathrm{~min}$ at 673 $\mathrm{K}$. The samples were exposed to air during transfer to the XPS setup.

sponding to an improved iron particle distribution. For both samples, fitting of the $\mathrm{O} 1 \mathrm{~s}$ spectra leads to two peaks. The contribution of $\mathrm{O}^{2-}$ in $\mathrm{Fe}_{2} \mathrm{O}_{3}$ is clearly resolved at $530.2 \mathrm{eV}$, which increases considerably corresponding to the increase of the iron particle distribution. Three factors may contribute to the peak at higher binding energies, that is, the oxygen-containing functional groups [28], and the $\mathrm{FeOOH}$ species formed due to the contact of metallic Fe with moisture in air after reduction [29], and adsorbed water on the surface, which cannot be removed in ultra high vacuum (UHV) conditions [30, 31]. Most of the oxygen-containing groups are believed to be removed by the reduction atmosphere at $1023 \mathrm{~K}$, although a small amount may form again upon contact with air. Assuming similar contributions from the adsorbed water, the difference of the high binding energy peaks of the two samples can be tentatively attributed to the $\mathrm{FeOOH}$ species. Therefore, the increased peak in the 

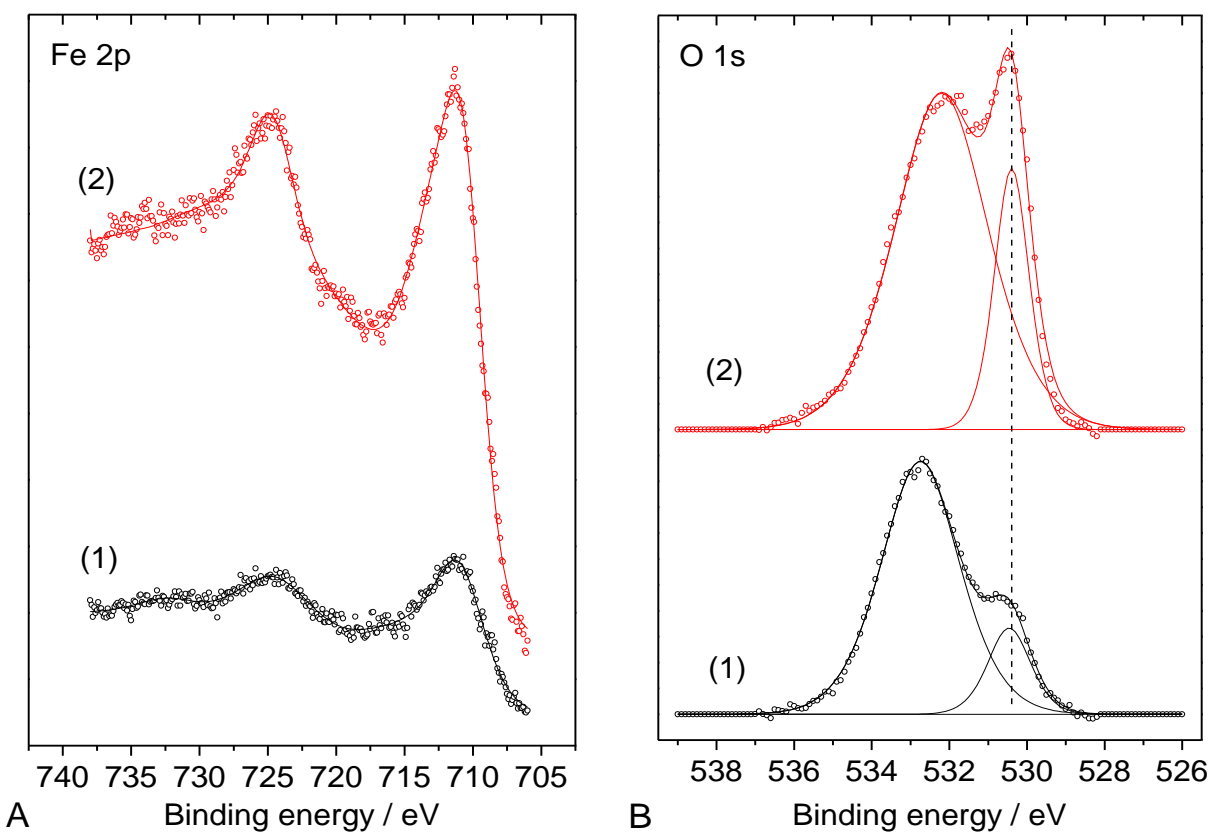

Fig. 4: XP Fe2p (A) and O1s (B) spectra of iron-loaded VGCFs. (1) VGCF-supported AFC was reduced directly by heating to $1023 \mathrm{~K}$ under a mixture of $\mathrm{H}_{2}$ and $\mathrm{He}(1: 1,200 \mathrm{sccm}$ total), with a holding period of $20 \mathrm{~min}$ at $673 \mathrm{~K}$; (2) VGCF-supported AFC was calcined at $573 \mathrm{~K}$ in air before reduction at the same conditions. The original data are denoted by circles.

calcined sample again indicates a better distribution of $\mathrm{Fe}$ species on the fiber surface. The elemental surface composition of both samples is summarized in Table 1. The surface atomic concentration of iron is nearly 3 times higher for the sample with calcination treatment. It is likely that metallic iron exists in the core of the nanoparticles, because the difference of oxygen concentration in the two samples is not proportional to that of iron. The effect of calcination is believed to be related to the gasification of carbon (Eq. 1), which occurs at the iron-carbon interface during calcination, resulting in enhanced interactions between the iron particles and the carbon substrate. Sintering at higher temperatures is thus hindered leading to smaller particles and a better dispersion [32]. However, the gasification will not cause visible structural damage to the carbon substrate because of the chemical state of the iron catalysts. Only metallic iron is active for the gasification, which is apparently not a stable phase of iron in the calcination conditions.

$$
\mathrm{C}+\mathrm{O}_{2} \rightarrow \mathrm{CO}_{2}
$$

Fig. 5A shows a SEM micrograph of the parent VGCFs with an average diameter and length of $1.5 \mu \mathrm{m}$ and $3 \mathrm{~mm}$, respectively. After nitric acid treatment, AFC impregnation, and calcination, secondary nanofibers were grown from cyclohexane at $1023 \mathrm{~K}$. Very few nanofibers were obtained without the acid treatment step due to the hydrophobic carbon surface rendering the deposition of iron species essentially impossible. Without the calcination step, the homogeneity of the secondary nanofibers was poor. A combination of the two steps leads to the growth of
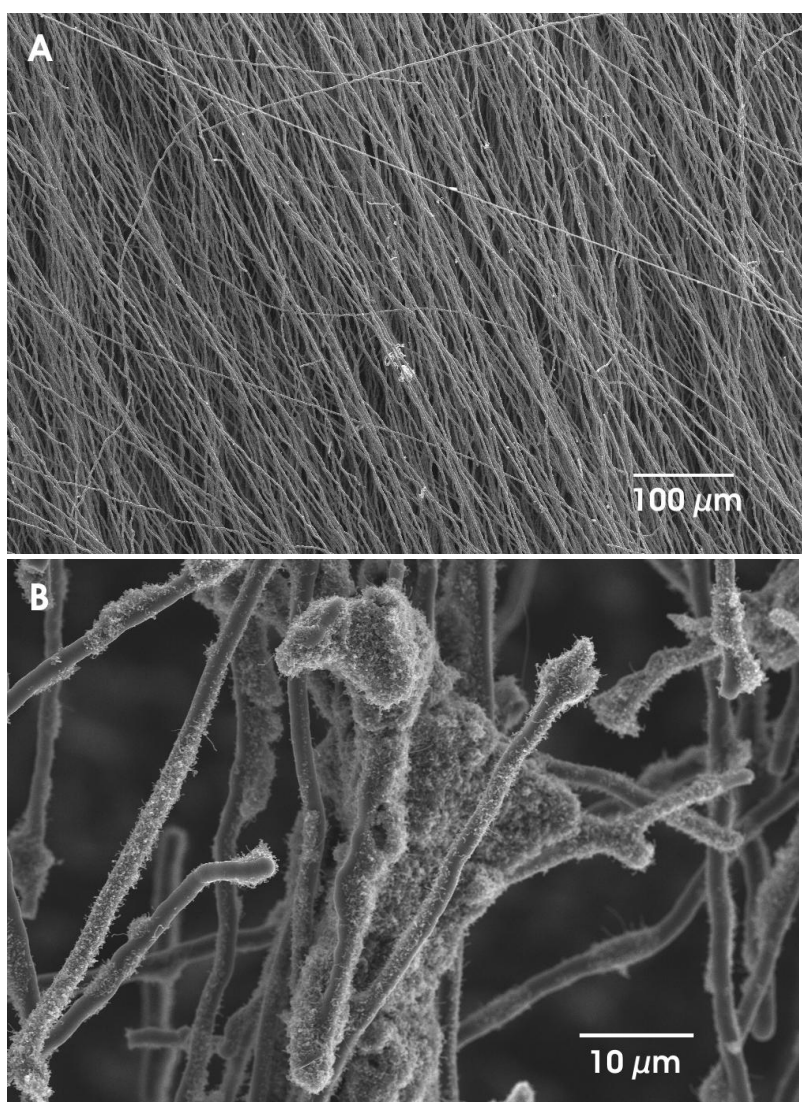

Fig. 5: SEM images of aligned VGCFs (the parent fibers) grown on graphite foil from cyclohexane at $1323 \mathrm{~K}(\mathrm{~A})$ and the secondary nanofibers grown on the VGCFs at $1023 \mathrm{~K}$ from cyclohexane for 30 min with $\mathrm{H}_{2}$ and $\mathrm{He}(2: 1)$ as carrier gas (B). 

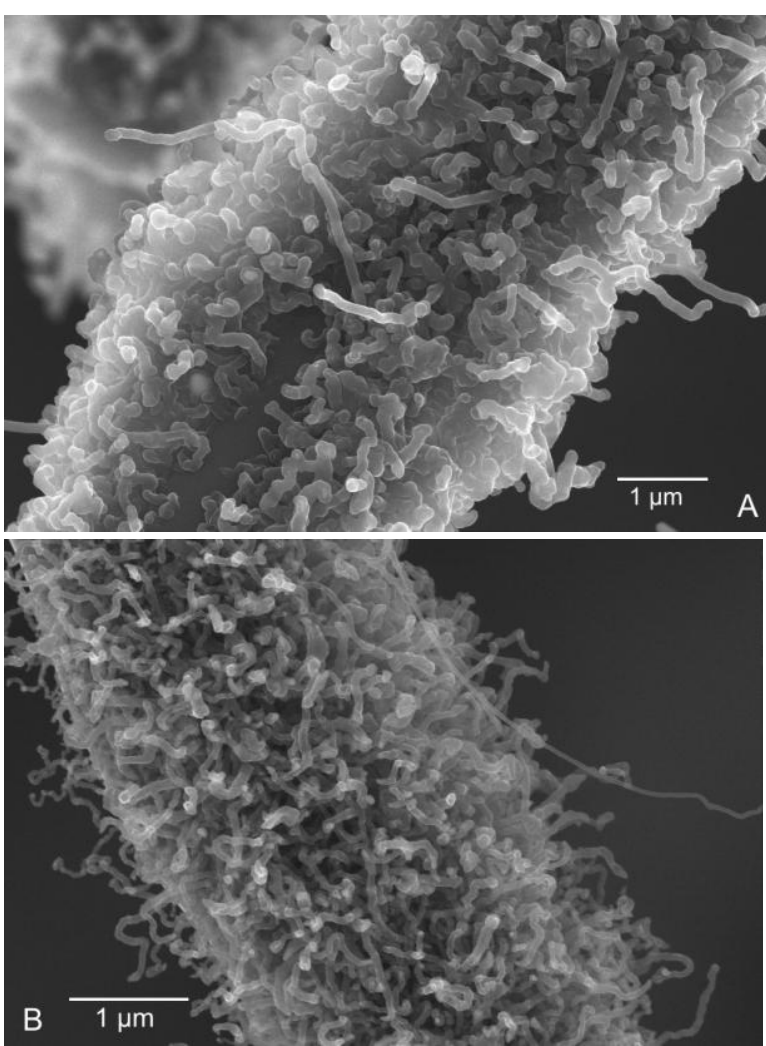

Fig. 6: SEM images of VGCF-supported nanofibers grown at 1023 $\mathrm{K}$ from cyclohexane with $\mathrm{He}$ as carrier gas (A) and with a mixture of $\mathrm{H}_{2}$ and $\mathrm{He}(2: 1)$ as carrier gas (B).

secondary nanofibers with homogeneous distribution (Fig. 5B). The specific surface area of the carbon composites was determined to be $106 \mathrm{~m}^{2} \mathrm{~g}^{-1}$, which is an increase by two orders of magnitude as compared to the parent VGCFs. Using the same temperature program, the presence of $\mathrm{H}_{2}$ can reduce the diameter of the secondary nanofibers from about $100 \mathrm{~nm}$ to $50 \mathrm{~nm}$ (Fig. 6A and 6B), which is due to the retarding effect of $\mathrm{H}_{2}$ on the pyrolytic deposition of carbon. In addition, $\mathrm{H}_{2}$ can promote the elongation of the filaments by preventing the deactivation of the iron catalysts. Moreover, the nanofiber homogeneity was also improved by $\mathrm{H}_{2}$, rendering more iron nanoparticles catalytically active.

Fig. 7A shows the result of thermogravimetric analysis of the VGCF-nanofiber composites (shown in Fig. 6B). The DTG curve is approximately a superposition of the DTG curves of nanofibers (Fig. 7B) and the parent VGCFs (Fig. 7C). Therefore, the first narrow peak at about $820 \mathrm{~K}$ of the DTG curve in Fig. 7A is due to the combustion of the secondary nanofibers, whereas the broad peak at about 900 $\mathrm{K}$ is due to the combustion of the VGCFs. The difference of their combustion temperatures can be attributed to the difference in dimensions of the parent VGCFs, the secondary nanofibers $(c a .50 \mathrm{~nm})$ and the commercial nanofibers (ca. $100 \mathrm{~nm}$ ). The nanofibers have a much larger surface area leading to faster oxidation at lower temperatures. On the contrary, the broad peak of the VGCFs is due to their shell and core structures, which were combusted subsequently within a longer period of time.

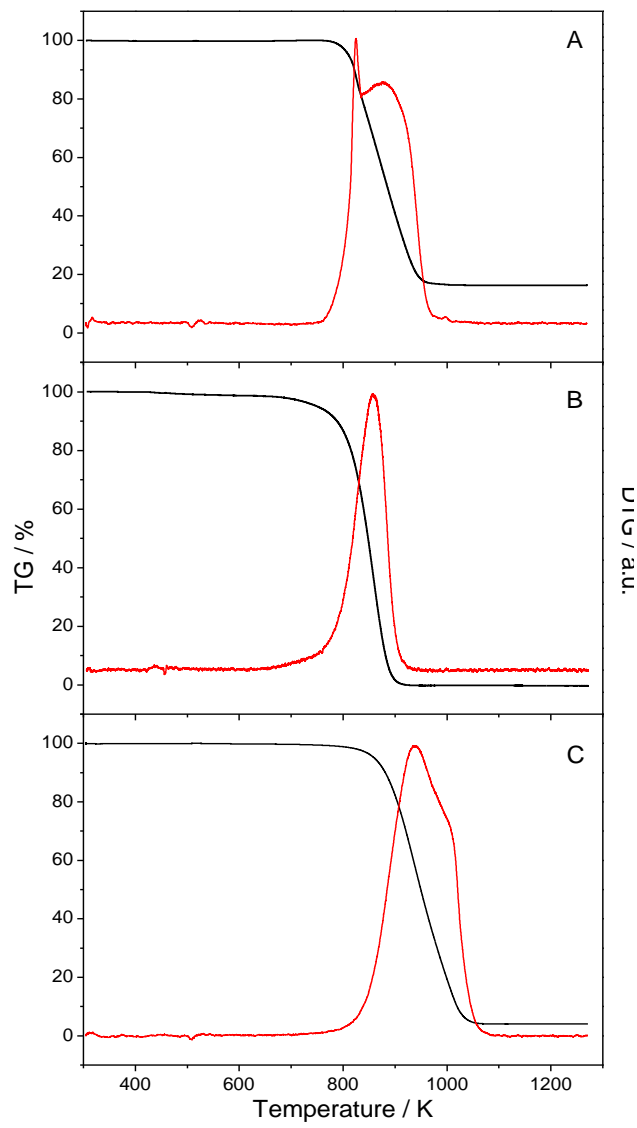

Fig. 7: Thermogravimetric weight loss curve and the corresponding differential curve of (A) VGCF-supported nanofibers, (B) the Pyrograf III nanofibers, and (C) the parent VGCFs. The measurements were performed in synthetic air $\left(20.5 \% \mathrm{O}_{2}\right.$ in $\mathrm{N}_{2}, 100 \mathrm{sccm}$ total) at a heating rate of $10 \mathrm{k} \mathrm{min}^{-1}$.

\section{Conclusions}

High resolution TEM studies found that the shell of the VGCFs consists of densely-packed domains embedded in loosely-packed matrix, both being highly disordered. Regular edge planes as observed on the surface of fishbone nanofibers do not exist. Hence, surface functionalization of the VGCFs is more important for the impregnation of AFC to introduce iron catalysts. It was found that the combined application of three steps, i.e., the surface oxidation by nitric acid, impregnation, and calcination can significantly improve the homogeneity of the impregnated iron catalyst particles, among which calcination is a key step. The effect of calcination can be attributed to enhanced interactions between iron and carbon because of the gasification of carbon occurring at the iron-carbon interface, where iron is the gasification catalysts. XPS studies demonstrated that the surface atomic concentration of both iron and oxygen increased considerably due to the calcination step. The growth of secondary nanofibers from cyclohexane was studied and homogeneously distributed nanofibers were obtained on VGCFs under optimized conditions. The specific surface area of the obtained composites was enhanced by two orders of magnitude up to $106 \mathrm{~m}^{2} \mathrm{~g}^{-1}$. The obtained 
VGCF-nanofiber composites are promising materials for structured catalyst supports in heterogeneous catalysis as well as for the enhancement of fiber-matrix interactions when embedding in polymers.

\section{References}

P. Serp, M. Corrias, P. Kalck, Appl. Catal. A 253 (2003) 337.

[2] A.J. Van Dillen, R.J.A.M. Terörde, D.J. Lensveld, J.W. Geus, K.P. De Jong, J. Catal. 216 (2003) 257.

[3] M.K. Van der Lee, A.J. Van Dillen, J.H. Bitter, K.P. De Jong, J. Am. Chem. Soc. 127 (2005) 13573.

[4] P. Serp, P. Kalck, R. Feurer, Chem. Rev. 102 (2002) 3085.

[5] W. Xia, D. Su, A. Birkner, L. Ruppel, Y. Wang, C. Wöll, J. Qian, C. Liang, G. Marginean, W. Brandl, M. Muhler, Chem. Mater. 17 (2005) 5737.

[6] L.A. Boot, A.J. van Dillen, J.W. Geus, F.R. van Buren, J. Catal. 163 (1996) 186.

[7] F.R. van den Berg, M.W.J. Craje, P.J. Kooyman, A.M. van der Kraan, J.W. Geus, App. Catal. A 235 (2002) 217.

[8] M.L. Toebes, J.M.P. Van Heeswijk, J.H. Bitter, A.J. Van Dillen, K.P. De Jong, Carbon 42 (2004) 307.

[9] H. Darmstadt, C. Roy, S. Kaliaguine, J.M. Ting, R.L. Alig, Carbon 36 (1998) 1183.

[10] H. Bubert, W. Brandl, S. Kittel, G. Marginean, D Toma, Anal. Bioanal. Chem. 374 (2002) 1237.

[11] J.H. Bitter, M.K. Van der Lee, A.G.T. Slotboom, A.J. Van Dillen, K.P. De Jong, Catal. Lett. 89 (2003) 139.

[12] R.T.K. Baker, Carbon 27 (1989) 315.

[13] O.F.K. Schlüter, B.I. Wehner, D. Hu, W. Xia, T. Quandt, G. Marginean, W. Brandl, M. Muhler, Appl. Catal. A 274 (2004) 71.

[14] P.V. Lakshminarayanan, H. Toghiani, C.U. Pittman Jr., Carbon 42 (2004) 2433.

[15] W. Xia, O.F.K. Schlüter, C. Liang, M.W.E. Van den Berg, M. Guraya, M. Muhler, Catal. Today 102 (2005) 34.

[16] W.B. Downs, R.T.K. Baker, Carbon 29 (1991) 1173.

[17] W.B. Downs, R.T.K. Baker, J. Mater. Res. 10 (1995) 625 .

\section{Acknowledgements}

The authors are indebted to the MWF/NRW for financial support. Wei Xia thanks the IMPRS of Surface and Interface Engineering in Advanced Materials (SurMat) for a research grant.

[18] S. Zhu, C.H. Su, S.L. Lehoczky, I. Muntele, D. Ila. Diamond Relat. Mater. 12 (2003) 1825.

[19] Z. Zhao, L. Ci, H. Cheng, J. Bai, Carbon 43 (2005) 663

[20] M.F. De Riccardis, D. Carbone, Th. Dikonimos Makris, R. Giorgi, N. Lisi, E. Salernitano, Carbon 44 (2006) 671.

[21] S. Tzeng, K. Hung, T. Ko, Carbon 44 (2006) 859

[22] S. Park, D. Lee, Carbon 44 (2006) 1930

[23] A. Laachachi, A. Vivet, G. Nouet, B.B. Doudou, C. Poilane, J. Chen, J. Bai, M. Ayachi, Mater. Lett. 62 (2008) 394

[24] Q. Zhang, W.Z. Qian, R. Xiang, Z. Yang, G.H. Luo, Y. Wang, F. Wei, Mater. Chem. Phys. 107 (2008) 317.

[25] G.A.M. Hussein, Powder Technol. 80 (1994) 265.

[26] M. Muhler, R. Schlögl, G. Ertl, J. Catal. 138 (1992) 413.

[27] T. Schedel-Niedrig, W. Weiss, R. Schlögl, Phys. Rev. B 52 (1995) 17449.

[28] M.T. Martinez, M.A. Callejas, A.M. Benito, M. Cochet, T. Seeger, A. Ansón, J. Schreiber, C. Gordon, C. Marhic, O. Chauvet, J.L.G. Fierro, W.K. Maser, Carbon 41 (2003) 2247.

[29] C.R. Brundle, T.J. Chuang, K. Wandelt, Surface Sci. 68 (1977) 459

[30] R. Schlögl, in: G. Ertl, H. Knözinger, J. Weitkamp (Eds.), Handbook of Heterogeneous Catalysis, WileyVCH, Weinheim, p.138.

[31] E. Desimoni, G.L. Casellas, A.M. Salvi, T.R.I. Castaldi, A. Morone, Carbon 30 (1992) 527.

[32] W. Xia, X. Chen, S. Kundu, X. Wang, G. Grundmeier, Y. Wang, M. Bron, W. Schuhmann, M. Muhler, Surf. Coatings Tech. 201 (2007) 9232.

[33] D. Briggs, M.P. Seah, Practical Surface Analysis, John Wiley \& Sons, England, 1994. 